\title{
Determinants of Under-Five Mortality in Bangladesh
}

\author{
Abdul Hamid Chowdhury \\ Department of Business Administration, International Islamic University Chittagong, Chittagong, Bangladesh \\ Email: ahamide@gmail.com
}

Received April 14, 2013; revised May 15, 2013; accepted May 23, 2013

Copyright (C) 2013 Abdul Hamid Chowdhury. This is an open access article distributed under the Creative Commons Attribution License, which permits unrestricted use, distribution, and reproduction in any medium, provided the original work is properly cited.

\begin{abstract}
This paper examines determinants of under-five mortality in Bangladesh. The study utilizes the data extracted from the 2007 Bangladesh demographic and health survey. Chi-square test for independence and multivariate proportional hazard analysis reflects that father's education, place of residence, region of residence, number of children under five years of age, previous death of sibling, mother's age and breastfeeding have significant influence on under-five mortality. The proximate determinants are found to have stronger influence on under-five mortality than the socioeconomic factors considered in the study do.
\end{abstract}

Keywords: Under-Five Mortality; Proportional Hazard; Significance; Determinant

\section{Introduction}

Under-five mortality, the probability of dying between birth and age 5 expressed per 1000 live births and a subject of great interest to social scientists and policy makers, are widely used as an indicator of the level of socioeconomic development and quality of life in less developed countries. Data indicate that some eleven million children under the age of five die annually in the world as a whole, of whom over ten million are in the developing world [1]. Bangladesh is a developing country in southeast Asia. Childhood mortality rates obtained for the five years preceding successive DHS surveys conducted in Bangladesh since 1993-1994 confirm a declining pattern. Between the periods 1990-1994 and 2003-2007, underfive mortality declined by 51 percent from 133 deaths per 1000 live births to 65 deaths per 1000 . One in fifteen children born in Bangladesh dies before reaching the fifth birthday.

Previous studies reveal that childhood mortality varies due to the variations of associated characteristics of the parents as well as children under five [2,3]. Focusing on 28 developing countries mostly in Asia and Latin America, Hobcraft et al. [4] found that mother's and husband's education, their work status and their residence were more or less associated with child survival. Da Vanzo et al. [5] in Malaysia found a higher risk of death to children born to mothers below 18 and above 40 years of age. Short preceding birth interval influences child mortality through three mechanisms. First, closely spaced births cause depletion of the mother [6]. Second mechanism is through sibling competition and the third is transition of infectious diseases between the closely spaced children [7]. The first one is the biological and the other two are behavioral effects of short preceding birth interval [8]. This paper attempts to identify the factors which influence the under-five mortality in Bangladesh.

\section{Data and Methods}

The analysis presented in this paper uses data collected in the Bangladesh Demographic and Health Survey conducted from March to August 2007. The BDHS, 2007 data comprise a total of 6150 births that occurred 5 years preceding the survey. Multiple births are excluded because they experience a higher risk of death linked with their multiplicity, which could distort the results [9]. Births happening during the month of interview are also excluded because their disclosure to neonatal is censored. Therefore, this analysis is limited to singleton births, born 1 - 59 months before the survey. To include the survival status of the older siblings of the analysis, only women are included who have at least two births.

Table 1 presents the number and percentage of births included in this work for studying differentials and determinants of childhood mortality in Bangladesh. Finally, we have considered 4003 births, which are about 65 percent of sample for analyzing child mortality.

The study develops a framework in which the socioeconomic variables affect the outcome through the four 
Table 1. Distribution of births five year preceding the survey, 2007.

\begin{tabular}{lcc}
\hline Particulars & Number & Percentage \\
\hline Total births & 6150 & 100.00 \\
First order births & 2039 & 33.15 \\
Two or more births & 4111 & 66.85 \\
Twin births & 85 & 2.07 \\
Singleton births & 4026 & 97.93 \\
Births during the month of the interview & 23 & 0.57 \\
Number of births included in the analysis & 4003 & 99.43 \\
Ultimate number of births & 4003 & 65.09 \\
\hline
\end{tabular}

proximate determinants namely, demographic factors, environmental factors, nutritional factors and health seeking behavior factors. The variables included in the framework under five broad heads are as follows:

Socioeconomic Variables: Parental education; socioeconomic status; place of residence; region of residence and religion of respondents. Demographic Factors: Age of the mother at the time of birth; birth order; birth interval; sex of the child; previous sibling death and Number of children under five years of age. Environmental Contamination: Source of drinking water; Toilet facilities and Housing construction material. Nutritional Factor: Breast feeding, body mass index. Health-seeking Behavior: Prenatal care; place of birth; tetanus injection before birth and contraceptive use.

The methodologies used to evaluate factors associated with childhood mortality include a variety of generalized linear models. For example, probability or rates models have been proposed by Hobcraft et al. [4], conditional logit models by Da Vanza and Habicht [10]; and proportional hazard models by Martin et al. [11]; and Retherford et al. [12].

Proportional hazard models are most commonly used and also more preferable to other statistical models in demographic studies [13]. For example, life table has been developed to study the probability of dying at various ages according to a specific criterion, such as education, sex, residence and so on. By contrast with logistic models, life tables can be used when the dependent variable is expressed as the elapsed between an initial event, such as birth, and a final event, such as death. Another advantage of life tables is that censored observations can be included in the study. When more than one or two factors are believed to influence the waiting time under study, however, life tables cannot be used effectively. This is so because life table techniques require that a separate set of age-specific mortality rates be calculated for each category. This procedure limits the number of covariates since the sample size becomes smaller and smaller as the number of subgroups increase. In such situations, hazard models are more appropriate technique over logistic regression model and life tables.

Considering its relevance the present study has employed Cox's proportional hazard model to assess the effects of selected variables on mortality rates. In this study, age in completed months of index children is considered as dependent variable. Age of dead children is calculated by subtracting date of birth of children from the date of death whereas; age of survived children is computed by subtracting date of birth from date of interview. Numbers of children who are surviving at the time of interview are considered as censored cases because their true duration of surviving could not be followed till death as the survey is retrospective.

\section{Results and Discussion}

Independent variables under different broad heads are tested by chi-square to study the association with neonatal mortality. Except religion of the respondents, sex of child and body mass index of mothers, all other variables have shown significant association with under-five mortality. To examine the effect of explanatory variables on under-five deaths, five models are fitted to the data considering all the explanatory variables found significant in bivariate analysis. The findings are presented in the Table 2. The results of Model-1 show that babies born to mothers with secondary and above education have lower risk of under-five mortality relative to mothers with no education. The hazard of under-five mortality of higher educated mothers is 46 percent lower than those of illiterate mothers. These results are in positive direction with the earlier studies, which show that no educated mothers experience more childhood mortality than educated mothers $[14,15]$. There are several explanations can be made where maternal education influences child mortality. More educated women adopt simple health knowledge contrary to fatalistic acceptance of health outcomes; they adopt alternatives in child care and recent treatments. Educated women are more capable of handling the possible causes, which can affect child health. Communication with doctors and nurses should be easier for educated women.

Table 2 further shows that in Model-1, children of fathers with primary and secondary and higher education have 4 percent and 42 percent lower risks of under-five deaths respectively compared to children of illiterate fathers. Father's education with secondary and above education has a strong significant negative effect on underfive deaths. Findings thus suggest that with the increasing level of father's education, there is a clear significant evidence of decreasing under-five mortality in Bangla- 
Table 2. Cox's proportional hazard estimates of relative risk of selected factors on under-five mortality, BDHS, 2007.

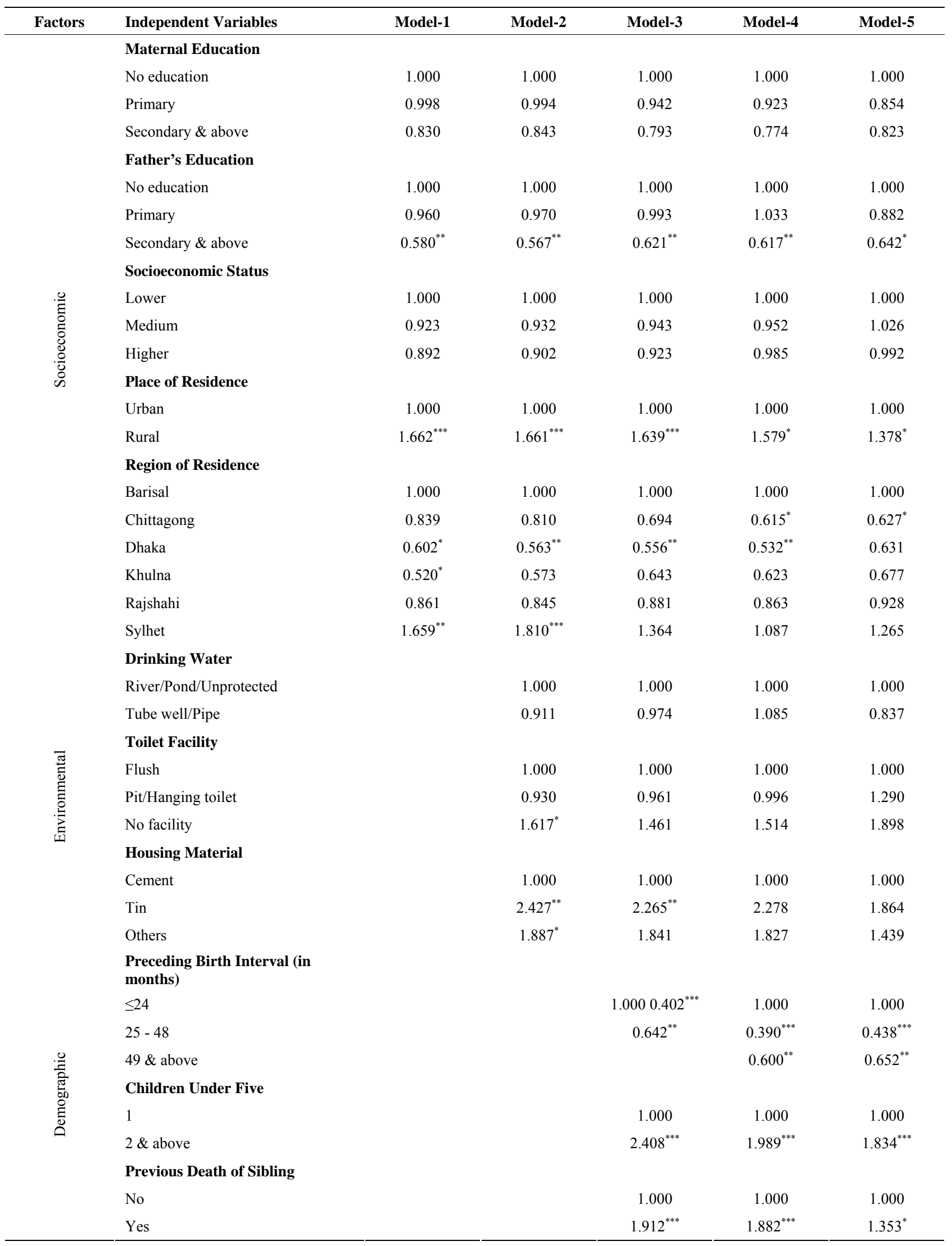




\begin{tabular}{|c|c|c|c|c|c|c|}
\hline & \multicolumn{6}{|l|}{ Birth Order } \\
\hline & \multicolumn{3}{|l|}{2} & 1.000 & 1.000 & 1.000 \\
\hline & \multicolumn{3}{|l|}{$3-4$} & 1.144 & 1.210 & 1.378 \\
\hline & \multicolumn{3}{|l|}{$5 \&$ above } & 1.325 & 1.477 & 1.382 \\
\hline & \multicolumn{6}{|l|}{ Mother's Age (in years) } \\
\hline & \multicolumn{3}{|l|}{$15-19$} & 1.000 & 1.000 & 1.000 \\
\hline & \multicolumn{3}{|l|}{$20-34$} & $0.643^{*}$ & $0.618^{* *}$ & $0.638^{*}$ \\
\hline & \multicolumn{3}{|l|}{$35-49$} & 0.797 & 0.773 & 0.834 \\
\hline & \multicolumn{6}{|l|}{ Contraceptive Use } \\
\hline & \multicolumn{4}{|l|}{$0=\mathrm{No}$} & 1.000 & 1.000 \\
\hline & \multicolumn{4}{|l|}{$1=\mathrm{Yes}$} & $0.548^{* * *}$ & $0.506^{* * *}$ \\
\hline & \multicolumn{6}{|l|}{ Place of Delivery } \\
\hline & \multicolumn{4}{|l|}{$1=$ Home } & 1.000 & 1.000 \\
\hline 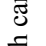 & \multicolumn{4}{|l|}{$2=$ Hospital /other places } & 0.912 & 0.934 \\
\hline ฮี & \multicolumn{6}{|l|}{ Prenatal Care } \\
\hline & \multicolumn{4}{|l|}{$0=$ No visit } & 1.000 & 1.000 \\
\hline & \multicolumn{4}{|l|}{$1=$ visits } & 0.989 & 0.992 \\
\hline \multirow{10}{*}{ 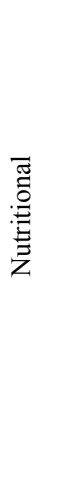 } & \multicolumn{6}{|c|}{ Tetanus Injection before Birth } \\
\hline & \multicolumn{4}{|l|}{$0=\mathrm{No}$} & 1.000 & 1.000 \\
\hline & \multicolumn{4}{|l|}{$1=\mathrm{Yes}$} & 0.916 & 0.926 \\
\hline & \multicolumn{6}{|l|}{ Breastfeeding } \\
\hline & \multicolumn{5}{|l|}{$0=\mathrm{No}$} & 1.000 \\
\hline & \multicolumn{5}{|l|}{$1=\mathrm{Yes}$} & $0.246^{* * *}$ \\
\hline & 2 log likelihood & 3090.23 & 3076.18 & 2988.80 & 2970.44 & 2780.94 \\
\hline & Chi-square & 60.40 & 73.37 & 185.84 & 213.26 & 1140.03 \\
\hline & DF & 12 & 17 & 25 & 29 & 30 \\
\hline & Significance & 0.000 & 0.000 & 0.000 & 0.000 & 0.000 \\
\hline
\end{tabular}

Note: ${ }^{* *} \mathrm{p}<0.01 ;{ }^{* *} \mathrm{p}<0.05 ;{ }^{*} \mathrm{p}<0.10$.

desh. This finding is in accordance with the results of other study. As for example, McDonald [16] found that attainment of secondary education by father was almost strongly associated with lower childhood mortality in Indonesia. Socioeconomic status of the respondents shows an insignificant effect on under-five mortality. However, babies born to mothers with higher and medium socioeconomic strata are more likely to survive compared to mothers belong to lower socioeconomic stratum.

A significant difference in under-five mortality is observed by place of residence of the respondents. The hazard analysis shows significantly higher under-five mortality for babies born to residents of rural areas compared to the babies born in urban areas. It shows that the hazard of under-five mortality for children of rural areas is almost 66 percent higher than the children born and brought up in urban areas.

This result supports the earlier findings, which show that rural mortality in developing countries has been higher than urban mortality [17-20]. The probable causes of higher under-mortality may be poor standard of living, weak access to public health sectors, delivery in unhygienic conditions and lower age at first marriage among women particularly in the rural areas.

The results obtaining from Model-1 also show that children living in Sylhet division have significantly higher under-five mortality compared to children living in Barisal division. Babies of mothers who are residing in Sylhet division have about 66 percent higher risk compared to babies of Barisal division. Children who are from Chittagong, Dhaka, Khulna and Rajshahi have 16, 40, 48 and 14 percent lower risk of under-five mortality respectively relative to children of Barisal division. Although the regional variations of under-five mortality are found pronounced in Bangladesh, the significant differences have been observed only in Dhaka, Khulna and Sylhet divisions. 
Model-2 is constructed after the inclusion of environmental factors with socioeconomic factors. It is observed from the model that the difference of under-five mortality in Khulna division has been disappeared. However, residence in Dhaka and Sylhet division still has a significant effect on under-five mortality. Moreover, father's education and place of residence also hold their position in the same magnitude in Model-2. It is expected that tube well or piped water is much better than the river or pond water because pond or river water account for water born disease like diarrhea and cholera, which are harmful for child health. The results of this study confirm such an assumption. The hazard analysis in the Model-2 reveals that babies whose families use drinking water from tube well or public tap or pipe have lower risk of under-five mortality relative to families depending on pond or river water. However, sources of drinking water show an insignificant effect on under-five deaths.

Improved toilet facilities in the household provide better hygiene. If not properly disposed of, human waste may result in contamination of food and water leading to acute diseases such as cholera. It is assumed that many of the deaths from infectious and parasitic diseases could have been averted by provision of proper sanitation. The hazard analysis shows that babies born to mothers living in households without any toilet facility have significantly higher under-five mortality than babies born to mothers living in households with a flush facility. Table 2 shows that the risk of under-five mortality is about 62 percent higher for children living in household without any toilet facility compared to the children living in houses with flush facilities.

It is hypothesized that houses built by baked brick (cemented) may be better hygienic than houses built by other materials. The results of Model-2 show that babies born to mothers living in houses constructed with tin and other ordinary materials, such as mud/bamboo have 2.43 and 1.89 times more likely to have under-five deaths respectively compared to children of mothers living in houses built by baked bricks. Houses constructed by tin have shown positive significant effect on under-five mortality.

In Model-3 when a bulk of demographic variables are added to socioeconomic and environmental variables, it is observed that father's education, place of residence, and houses constructed by tin still maintain their significance on under-five mortality. However, the significance of region of residence is disappeared after inclusion of all other socioeconomic, environmental, and demographic variables in the model.

The results of Model-3 show that the presence of preceding birth interval has a significant effect on under-five mortality. The mortality risk of babies born within the interval of $25-48$ months of a previous child is about 60 percent lower than the babies born within interval of two years and the difference is found highly statistically significant. Babies born within the interval of 49 and more months also have about 36 percent lower risk of underfive mortality than the babies born within 24 months of a preceding child. The findings indicate that the risk of under-five mortality decreases with increasing length of the preceding birth interval. The findings are in accordance with previous research works [5,6,21-23]. A short birth interval may imply that the mother has not had sufficient time to regain her physiological capacities or her nutritional status. It may deteriorate of the mother's capacities to adequately host a foetus and facilitate its normal growth process. These conditions can result in the early termination of a pregnancy, a premature live birth, and low weight at birth. The conditions of prematurity and low birth weight lead to a higher risk of death. Another adverse consequence of a short previous birth interval is the likely impairment of the mother's capacity to produce breast milk. This may be as an outcome of either nutritional depletion or physiological weakness, resulted from too closely spaced pregnancies.

The multivariate hazard analysis also shows that babies whose birth orders are of $3-4$, and 5 and above have higher risk of under-five mortality than babies whose birth orders are 2 . One of the main reasons of higher risk of under-five mortality may be siblings' competition for enjoying family resources among themselves. The children of higher birth order are more likely to be born to older mothers who are physically worn out and these children face competition from older siblings for food and other resources [24]. The distribution of household resources depends on the number of children in the household. Hence, a large number of children indicate a smaller share of scare resources. Lack of adequate resources to meet the nutritional requirements of growing children may result in under-nutrition. This relationship between higher birth order and stunting was also found to be positive among children in the Philippines [25]. However, in this study the differences of under-five mortality by birth order are not found statistically significant.

Number of children under five years of age of women has strong effect on under-five mortality. Babies born to mothers who have two or more than two children underfive years of age have 2.41 times higher chances of underfive mortality compared to babies of mothers who have only one child of less than five years of old. The relative risk of under-five mortality for children born to mothers aged $25-34$ is 36 percent lower than the babies born to mothers of age less than 20 years and the difference is found significant. Children of mothers whose age between 35 and 49 years have about 20 percent lower risk of under-five mortality compared to babies of mothers aged 15 - 19. The findings indicate that babies of rela- 
tively youngest mothers have highest under-five mortality.

The results in Model-3 also show that risk of underfive mortality for index children is 1.91 times higher for those whose mothers have already lost previous sibling than those who did not experience a sibling death earlier and the difference is highly statistically significant. Siblings' deaths tend to be correlated due to the same risks associated with the home environment and with their mother's health and reproductive behavior $[9,26]$.

Model-4 is fitted while including health care factors with socioeconomic, demographic and environmental factors in Model-3. The results of Model-4 show that father's education with secondary and higher, rural residence, preceding birth interval, number of children under five years of age, previous death of siblings are still maintain their significant effect on under-five mortality. In addition, babies of mothers who are living in Chittagong and Dhaka divisions have also shown significant effect on under-five mortality.

The results of Model-4 further show that contraceptive use is found one of the important significant predictors in reducing under-five mortality. Children of mothers who have ever used contraceptives have about 45 percent lower likelihood of under-five mortality compared to babies of mothers who never used any method. One of the important possible reasons for lower under-five mortality may be the longer birth intervals among the users.

The result of hazard analysis shows that prenatal care is negatively associated with under-five mortality. Children born to mothers who visit for prenatal care have lower under-five mortality than children born to mothers who do not visit for the same. However, the difference is not found statistically significant. It is often assumed that delivery in hospital is relatively safe for both mother as well as their children. The results of Model-4 show that babies delivered at hospitals have 9 percent lower risk of under-five mortality compared to the babies delivered at mother's home, which is in agreement with the predetermined assumption.

Among the factors, tetanus vaccine is an important for both mothers and infants. Findings in Table 2 reveal that children born to mothers who received tetanus injection before birth have about 7 percent lower risk of under-five mortality than children whose mothers did not receive tetanus. However, tetanus has not found any significant effect on under-five mortality.

Model-5 is fitted to the data including nutritional factors with socioeconomic, demographic, environmental and health care factors. Breastfeeding is often considered as an important determinant of infant and child mortality in developing countries. The hazard analysis of this study shows that breastfeeding has a strong significant effect on under-five mortality. The relative risk of under-five mortality is 75 percent lower of those children whose mother have breastfed their children compared to children whose mothers did not provide breastfeed. The result is in expected direction with findings obtained elsewhere. Huffman and Lamphere [27] stated that the child survival depends upon adequate nutrient intake and the ability of a child to resist or recover from infection. It has been found that breastfeeding appears to meet the nutritional requirements for the normal growth of a post neonatal for at least six months [28]. Consumed in sufficient quantities, breast milk can provide protection against malnutrition syndromes. Breastfeeding is also related to intervals between births because it affects birth spacing by lengthening postpartum amenorrhea period and by influencing the time from menses to conception [29].

\section{Conclusion}

To examine the effect of independent variables which are found significant in chi-square test for independence on childhood mortality in Bangladesh, the multivariate proportional hazards analysis is employed. To assess the independent effect of socioeconomic factors and interaction effect of all factors, separate models are fitted to the data accordingly. The proportional hazard estimates show that father's education, place of residence, region of residence, number of children under five years of age, previous death of sibling, mother's age and breastfeeding have significant effect on under-five mortality. Moreover, contraceptive use and preceding birth interval have highly significant effect on childhood mortality. The findings of this analysis do not fully support the hypothesis that socioeconomic factors affect childhood mortality only through the proximate determinants as proposed in the framework. However, it has been observed that socioeconomic factors have both their independent and indirect effect in reducing childhood mortality in Bangladesh. Furthermore, the results show that the proximate determinants have stronger impact on childhood mortality than that of the socioeconomic factors. Therefore, it may be concluded from the findings of all models that increasing paternal care, providing more civic facilities in vast rural areas, motivating the couples for using modern contraceptive methods for longer birth intervals and also persuading mothers for full breastfeeding practices could reduce childhood mortality in Bangladesh.

\section{REFERENCES}

[1] A. Amouzou and K. Hill, "Child Mortality and Socioeconomic Status in Sub-Saharan Africa," African Population Studies, Vol. 19, No. 1, 2004, pp. 1-11.

[2] S. A. Preston, "Mortality and Development Revisited," Quantitative Studies of Mortality Decline in the Devel- 
oping World (World Bank Staff Working Papers Number 683, Population and Development Series Number 8), The World Bank, Washington DC, 1985.

[3] World Bank, "World Development Report 1993: Investing in Health," Oxford University Press, New York, 1993.

[4] J. N. Hobcraft, J. W. Mc Donald and S. O. Rutstein, "Socio-Economic Factors in Infant and Child Mortality: A Cross-National Comparison," Population Studies, Vol. 38, No. 2, 1984, pp. 193-223.

[5] J. DaVanzo, W. P. Butz and J. P. Habicht, "How Biological and Behavioral Influences on Mortality in Malaysia Vary during the First Year of Life," Population Studies, Vol. 37, No. 3, 1983, pp. 381-402.

[6] C. De Sweemer, "The Influence of Child Spacing on Child Survival," Population Studies, Vol. 38, No. 1, 1984, pp. 47-72.

[7] A. K. Majumder, M. May and P. D. Pant, "Infant and Child Mortality Determinants in Bangladesh: Are They Changing?" Journal of Biosocial Science, Vol. 29, No. 4, 1997, pp. 385-399. doi:10.1017/S0021932097003854

[8] M. A. Koenig, J. F. Phillips, O. M. Campbell and S. D'Souza, "Birth Intervals and Childhood Mortality in Rural Bangladesh," Demography, Vol. 27, No. 2, 1990, pp. 251-265. doi:10.2307/2061452

[9] S. L. Curtis, I. Diamond and J. W. McDonald, "Birth Interval and Family Effects on Post Neonatal Mortality in Brazil," Demography, Vol. 30, No. 1, 1993, pp. 33-43. doi: $10.2307 / 2061861$

[10] J. DaVanzo and J. P. Habicht, "Infant Mortality Decline in Malaysia, 1946-1975: The Role of Changes in Variables and Changes in the Structure of Relationships," Demography, Vol. 23, No. 2, 1986, pp. 1-18. doi: $10.2307 / 2061613$

[11] L. G. Martin, J. Trussell, F. R. Salvail and N. M. Shah, "Co-Variates of Child Mortality in the Philippines, Indonesia, and Pakistan: An Analysis Based on Hazard Models," Population Studies, Vol. 37, No. 3, 1983, pp. 417432.

[12] R. D. Retherford, M. K. Choe, S. Thapa and B. B. Gubhaju, "To What Extent Does Breastfeeding Explain Birth Interval Effects on Early Childhood Mortality," Demography, Vol. 26, No. 3, 1989, pp. 439-450. doi: $10.2307 / 2061603$

[13] J. Menken, J. Trussel, D. Stempel and O. Babakol, "Proportional Hazards Life Table Models: An Illustrative Analysis of the Socio-Demographic Influences on Marriage Dissolution in the United States," Demography, Vol. 18, No. 2, 1981, pp. 181-200. doi:10.2307/2061092

[14] M. Murphy and D. Wang, "Do Previous Birth Interval and Mother's Education Influence Infant Survival? A Bayesian Model Averaging Analysis of Chinese Data," Population Studies, Vol. 55, No. 1, 2001, pp. 37-47. doi:10.1080/00324720127679

[15] G. Bicego and O. B. Ahmad, "Infant and Child Mortality, Demographic and Health Surveys, Comparative Studies No. 20," Macro International, Calverton, 1996.

[16] P. McDonald, "The Equality of Distribution of Child
Mortality," Bulletin of Indonesian Economic Studies, Vol. 16, No. 3, 1980, pp. 115-119. doi: $10.1080 / 00074918012331333869$

[17] A. K. Jain, "Determinants of Regional Variations in Infant Mortality in Rural India," Population Studies, Vol. 39, No. 3, 1985, pp. 407-424. doi:10.1080/0032472031000141596

[18] L. Visaria, "Infant Mortality in India, Level, Trends and Determinants," Economic and Political Weekly, Vol. 20, No. 2, 1985, pp. 1352-1359.

[19] A. Farah and S. H. Preston, "Child Mortality Differentials in Sudan," Population and Development Review, Vol. 8, No. 2, 1982, pp. 365-384. doi:10.2307/1972992

[20] V. C. Chidambaram, J. McDonald and M. D. Bracher, "Infant and Child Mortality in the Developing World: Information from the World Fertility Survey," International Family Planning Perspectives, Vol. 11, No. 1, 1985, pp. 17-25. doi: $10.2307 / 2947860$

[21] J. G. Cleland and Z. A. Sathar, "The Effect of Birth Spacing on Childhood Mortality in Pakistan," Population Studies, Vol. 38, No. 3, 1984, pp. 401-418.

[22] B. B. Gubhaju, "Effect of Birth Spacing on Infant and Child Mortality in Rural Nepal," Journal of Biosocial Science, Vol. 18, No. 4, 1986, pp. 435-448. doi:10.1017/S002193200001645X

[23] J. N. Hobcraft, J. W. McDonald and S. O. Rutstein, "Demographic Determinants of Infant and Early Child Mortality: A Comparative Analysis," Population Studies, Vol. 39, No. 3, 1985, pp. 363-385. doi:10.1080/0032472031000141576

[24] S. O. Rutstein, "Infant and Child Mortality: Levels, Trends and Demographic Differentials," Revised Edition, Comparative Studies No. 43, International Statistical Institute, Voorburg, 1984.

[25] S. Horton, "Birth Order and Child Nutritional Status: Evidence from the Philippines," Economic Development and Cultural Change, Vol. 36, No. 2, 1988, pp. 341-354. doi: $10.1086 / 451655$

[26] M. Das Gupta, “Death Clustering, Mothers' Education and the Determinants of Child Mortality in Rural Punjab, India," Population Studies, Vol. 44, No. 3, 1990, pp. 489505. doi:10.1080/0032472031000144866

[27] S. L. Huffman and B. B. Lamphere, "Breastfeeding Performance and Child Survival," In: W. H. Mosley and L. C. Chen, Eds., Child Survival: Strategies for Research, Population and Development Review, Vol. 10, 1984, pp. 93116.

[28] J. D. Wray, "Maternal Nutrition, Breastfeeding and Infant Survival," In: W. H. Mosley, Ed., Nutrition and Human Reproduction, Plenum Press, New York, 1978. doi:10.1007/978-1-4684-0790-7 12

[29] L. S. Adair, B. M. Popkin and D. K. Guilkey, “The Duration of Breastfeeding: How Is It Affected by Biological, Socioeconomic, Health Sector and Food Industry Factors?" Demography, Vol. 30, No. 1, 1993, pp. 63-80. doi: $10.2307 / 2061863$ 